\title{
Effects of Blood Flow Restriction and Different Support Surfaces on the Thickness of Type-I Muscle Fibers in the Trunk
}

\author{
Jae-Cheol Park', Seung-Keun Oh'1, Jin-Gyu Jeong ${ }^{2}$ \\ 'Department of Physical Therapy, Graduate School, Nambu University, Gwangju; '2Department of Physical Therapy, Chunnam Techno University, \\ Chunnam, Korea
}

Purpose: This study was conducted to investigate the effects of blood flow restriction and different support surfaces for bridge exercises on the thickness of the transverse abdominis and multifidus, which are trunk-stabilizing muscles.

Methods: The study's subjects were 45 adults who were divided into three groups that performed bridge exercises over a six-week period on their respective support surfaces after blood flow restriction. Changes in the thickness of the subjects' transverse abdominis and multifidus muscles were measured using ultrasonography before the experiment, then three and six weeks after the experiment. The changes in each variable over time were analyzed using a repeated-measures analysis of variance (ANOVA).

Results: The transverse abdominis showed significant differences in muscle thickness with regard to time and the interaction between time and each group $(p<0.05)$, but no significant differences with regard to changes among groups $(p>0.05)$. The multifidus showed significant differences in muscle thickness with regard to time, the interaction between time and each group, and changes between groups $(\mathrm{p}<0.05)$.

Conclusion: Blood flow restriction and different support surfaces for bridge exercises led to significant differences in the thickness of the transverse abdominis and multifidus. This study's results may be used as the basis for future studies and for rehabilitation in clinical practice.

Keywords: Blood flow restriction, Thickness, Ultrasonography, Bridge exercise

\section{서 론}

일상생활에서 몸통 주위의 근육들은 자세 조절과 움직임에 중요한 역할을 하며, 이를 통해 안정적인 근력 활동이 가능해진다.1,2 몸통부 의 안정성을 얻기 위해서는 표재성 근육과 심부성 근육의 근력과 지 구력이 필요하며 근육의 동시 수축이 중요하다. 몸통의 안정화에 가 장 큰 역할을 담당하는 근육은 배가로근과 뭇갈래근이다. ${ }^{4}$ Stevens 등 ${ }^{5}$ 은 배속빗근, 배가로근 그리고 허리뼈 심부근이 허리 안정성을 제공 하고 뭇갈래근은 해당 척추의 작은 움직임을 조절한다고 하였다. 이 러한 심부성 근육의 약화 시 몸통부의 불안정성을 일으키며 정형 외 과적 질환이 발생하기 때문에 몸통 근육의 강화는 몸통 안정화와 재 활에 있어서 필수이다.

이곳의 강화를 위해 자세의 변화 및 다양한 도구의 사용 또는 지면 차이를 두고 다양하게 시행되는, 몸통 안정화 훈련 연구가 진행되었
으며, ${ }^{6-10}$ 특히 도구를 이용하여 불안정면을 적용하는 것은 자세 안정 성을 유지 하기 위해 요구되는 근육의 작용을 증가시키는 장점으로 알려져 있다."1 자세 변화로는 대표적으로 네발기기(bird dog), 교각 (bridge) 운동, 플랭크(plank) 운동 등이 있으며, 그 중 교각 운동은 임 상에서 많이 사용되며 물리치료실에서 몸통 근재교육에 많이 이용 되고 있다. 낮은 강도의 운동을 필요로 하는 임상 치료 환경에서 몸 통 안정화를 위하여 교각 운동을 시행하는 것이 도움된다고 강조하 였고, ${ }^{12}$ 신체 균형을 지속하기 위한 주된 운동프로그램으로 자리매김 하고 있으며 몸통의 안정화와 관련한 운동조절 훈련에 높은 의의를 두고 있다. ${ }^{13}$ 단점으로 저항이 없고 유산소 훈련에 속하는 안정화 운 동은 I형 근섬유의 두께 증가를 위해서는 오랜 훈련 시간과 기간이 필요하며 그마저도 낮은 두께 증가에 그치고 있다. 두께 증가를 위해 서는 1RM (repetition maximum)의 70-80\%의 부하 운동과 반복 저항 운동이 일반적으로 권장 된다. ${ }^{14}$ 하지만 심혈관계 질환 환자나 만성질 
환 노인, 초기 재활에 임하는 사람에겐 저항 운동은 또 다른 질병과 부상을 발생시키기 때문에 사용을 금기시하고 있다. 훈련 강도가 낮 은 몸통 안정화와 고강도 훈련에 대한 대안적 접근법은 혈류제한을 동반한 저강도 몸통 안정화 훈련일 것이다.

지난 10 년 동안 가압 운동이라고 불리는 혈류 제한과 결합한 저강도 저항 운동이 전통적인 고강도 저항운동을 하는 동안에 유발하는 것 과 비슷한 근육 비대와 강도 이득을 유발한다는 것이 발표됐다.15,16 이 러한 혈류 제한운동은 몸통 안정화 운동과 고강도 저항 훈련의 단점 들을 보완하여, 보다 쉽게 $1 \mathrm{RM}$ 의 $20-30 \%$ 저강도 운동에서 $1 \mathrm{RM}$ 의 $70-$ $80 \%$ 고강도 운동방식과 유사한 운동 효과를 나타내고 있다. ${ }^{17}$ 혈류 제 한 운동은 근비대, 18,19 근력의 향상,20,21 근지구력의 향상,22 성장호르몬 분비 촉진, ${ }^{23}$ 등과 같이 고강도 저항 훈련과 동일한 효과를 보고 하고 있다. 선행연구들을 통해 혈류 제한 운동의 긍정적인 효과는 많이 보 고 되고 있지만 대부분이 II 형 근섬유를 대상으로 하고 있으며, 18,19,22,24 초음파를 이용하여 몸통 안정화에 중요한 I형 근섬유의 영상구조적 특성 변화에 대한 연구는 매우 부족한 실정이다.

따라서 본 연구에서는 짐볼과 교각운동을 이용한 혈류 제한 여부 차이에 따른 I형 근섬유인 배가로근근과 뭇갈래근의 두께를 초음 파를 이용하여 분석 연구함으로써 임상 재활 치료에 기초 자료로 활 용하는데 목적이 있다.

\section{연구 방법}

\section{1. 연구대상}

본 연구는 전남지역 20 대 건강한 성인 남성 30 명 여성 15 명 총 45 명 대 상으로 하였다. 각 군 별로 남성 10 명, 여성 5 명씩 배정하여 혈류 제한 과 짐볼에서 교각 운동군(blood flow restriction bridge exercise group on unstable surface, BBG-U) 15명, 혈류 제한과 안정면에서 교각 운동 군(blood flow restriction bridge exercise group on stable surface, BBG-S) 15 명, 교각 운동군(bridge exercise group, BG) 15명으로 나누어 실험을 하였고, 수축기와 확장기 혈압이 $140 \mathrm{mmHg}, 90 \mathrm{mmHg}$ 을 넘지 않는 자, 정형 외과적 질환 및 6 개월 이상 정기적인 운동을 하지 않은 자, 운 동 프로그램을 수행할 수 없는 대상자는 제외하였다. 연구를 시작하

Table 1. General characterisrics of subjects

\begin{tabular}{lcccc}
\hline & BBG-U $(\mathrm{N}=15)$ & $\mathrm{BBG}-\mathrm{S}(\mathrm{N}=15)$ & $\mathrm{BG}(\mathrm{N}=15)$ & $\mathrm{p}$ \\
\hline Age (year) & $21.9 \pm 1.33$ & $21.4 \pm 1.40$ & $22.1 \pm 1.35$ & 0.121 \\
Height $(\mathrm{cm})$ & $169.8 \pm 5.84$ & $170.0 \pm 6.94$ & $170.0 \pm 7.69$ & 0.730 \\
Weight $(\mathrm{kg})$ & $70.3 \pm 14.73$ & $72.6 \pm 17.14$ & $70.00 \pm 13.58$ & 0.559 \\
BMI $\left(\mathrm{kg} / \mathrm{m}^{2}\right)$ & $24.2 \pm 3.88$ & $24.9 \pm 4.96$ & $24.20 \pm 3.90$ & 0.297 \\
\hline
\end{tabular}

BBG-U: blood flow restriction bridge exercise group on unstable surface, BBG-S: blood flow restriction bridge exercise group on stable surface, BG: bridge exercise group, BMI: body mass index.
기 전 연구 목적과 방법을 설명하였고 연구 참여 동의서를 작성 후 본 연구를 시작하였다. 실험 대상자 분류는 연구자의 임의 배정 방식에 의하여 무작위로 설정되었으며, 실험 전 동질성 검정 결과 연령, 신장, 체중, BMI지수에서 유의한 차이가 없어 동일한 집단임을 확인하였 고 일반적 특성은 Tablel과 같다.

\section{2. 실험방법}

혈류 제한은 혈압계를 이용하여 만든 간이 벨트를 BBG-U와 BBG-S 에 각각 좌.우 팔의 겨드랑이 바로 아래 몸쪽 부위와 다리의 좌·우 샅고랑부분의 몸쪽 부분에 운동이 방해되지 않도록 적용하였다. 혈 류 제한 벨트의 압력은 BBG-U은 누운 자세에서 팔과 다리에 130 $\mathrm{mmHg}$ 의 압력을 주었고, 1 주 간격으로 $10 \mathrm{mmHg}$ 압력을 점진적으로 증가하여 3주 후부터 팔과 다리에 $150 \mathrm{mmHg}$ 를 적용하여 총 6주간 운동을 실시하였고, BBG-S은 BBG-U와 동일한 자세에서 $100 \mathrm{mmHg}$ 의 압력을 6 주간 적용하여 운동을 하였다. BBG-U의 운동 자세는 바 로 누운 자세에서 무릎관절을 굽힘 하여 짐볼에 발바닥을 대고 다리 의 각도는 $45^{\circ}$ 로 유지하였으며 손은 몸통 옆에 나란히 두었고 시작과 동시에 어깨뼈가 바닥에서 떨어지도록 골반 부분을 들어 올려 등척 성 운동을 하였다. BBG-S는 안정면에서 바로 누운 자세로 무릎 관절 을 $90^{\circ}$ 굽힘하여 시작과 동시에 골반 부분을 들어 올려 등척성 운동 을 하였다. 중재는 총 6 주간주 3 회 1 일 30 분씩 중재하였다.

\section{1) 측정도구}

근육의 두께 측정을 위한 초음파 영상 수집은 초음파 영상 장치를 (Mylabone, Esaote Italy) 이용하여 측정하였으며, 이 장치의 주파수 변 조 범위는 $9 \mathrm{MHz}$ 이고 gain의 범위는 $20-80$, 초음파 변환기는 $7.5 \mathrm{MHz}$ 선형탐촉자(linear transducer)이다. 측정자 간의 차이를 최소화하기 위해 복부에 대한 해부학적 지식과 초음파 검사에 숙달된 물리치료 사 1 인의 측정자가 검사하였다. 근육 측정 자세는 반드시 누운 자세 를 취하고 배꼽에서 바깥쪽으로 $13 \mathrm{~cm}$, 앞위엉덩뼈가시(ASIS)에서 직 선이 만나는 지점에서 초음파 화면에 배바깥빗근이 왼쪽 가장자리 에 위치 하게 설정하여 배가로근을 측정하였고, 호흡이 근두께에 영 향을 미칠 것을 고려하여 호기 후 호흡을 멈춘 상태에서 측정하였 다. ${ }^{25}$ 뭇갈래근의 측정은 엎드려 누운 자세를 취한 후 척추 앞굽음의 감소를 위해 복부에 배개를 넣은 후 4-5번 부분의 가시돌기와 뒤위엉 덩뼈가시(PSIS)사이에 있는 근육을 초음파에 내장된 켈리퍼를 이용 하여 뼈와 근막까지 거리를 측정하여 분석하였다. 측정 부위를 정확 히 유지 하기 위해 유성펜으로 표시한 후 시행하였으며, 피부의 압박 을 최소화하기 위해 충분한 양의 초음파 겔(Dayo medical Co., PROGEL-II, Korea)를 도포하였다. 측정이 일정하게 되도록 변화기를 피부 와 직각으로 유지하여 좌측 근육만 측정 하였으며 3 회 반복 측정 후 
Table 2. Comparison of transversus abdominis and multifidus muscle thickness

(unit: $\mathrm{mm}$ )

\begin{tabular}{|c|c|c|c|c|c|c|c|c|}
\hline & & \multirow{2}{*}{ Pre } & \multirow{2}{*}{ 3weeks } & \multirow{2}{*}{6 weeks } & \multicolumn{4}{|c|}{$\mathrm{F}$} \\
\hline & & & & & Time & Group & TimeX Group & Post-hoc \\
\hline \multirow[t]{3}{*}{ TrA-T } & BBG-U & $2.64 \pm 0.61$ & $3.30 \pm 0.55$ & $4.00 \pm 0.53$ & & & & \\
\hline & BBG-S & $2.66 \pm 0.76$ & $3.22 \pm 0.69$ & $3.80 \pm 0.69$ & $394.631^{*}$ & 1.806 & $38.882^{*}$ & $a, b, c$ \\
\hline & BG & $2.70 \pm 0.72$ & $2.88 \pm 0.71$ & $3.09 \pm 0.65$ & & & & \\
\hline \multirow[t]{3}{*}{ MF-T } & $B B G-U^{a}$ & $1.63 \pm 0.30$ & $2.18 \pm 0.33$ & $2.93 \pm 0.31$ & & & & \\
\hline & $B B G-S^{b}$ & $1.62 \pm 0.38$ & $2.11 \pm 0.34$ & $2.63 \pm 0.33$ & $778.085^{\star}$ & $4.150^{*}$ & $60.256^{*}$ & $a>c$ \\
\hline & $B G^{c}$ & $1.67 \pm 0.43$ & $1.83 \pm 0.43$ & $2.11 \pm 0.43$ & & & & \\
\hline
\end{tabular}

TrA-T: transversus abdominis thickness, MF-T: multifidus thickness, BBG-U: blood flow restriction bridge exercise group on unstable surface, BBG-S: blood flow restriction bridge exercise group on stable surface, BG: bridge exercise group. ${ }^{\star} p<0.05$.

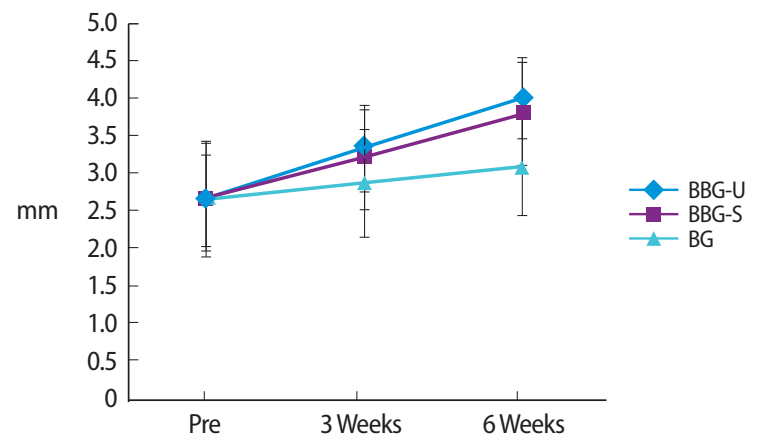

Figure 1. Comparison of transversus abdominis muscle thickness.

그 평균값을 근육의 두께로 정하였다.

\section{2) 분석방법}

모든 자료는 SPSS ver 19.0 통계 프로그램을 이용하여 분석하였고 세 그룹의 운동 전과 운동 3 주 후, 운동 6 주 후의 측정 변인에 대한 변화 를 알아보기 위해 반복측정 분산분석(repeated measures ANOVA)을 이용하였다 사후검정으로는 Scheffe 다중비교분석을 하였다. 통계학 적 유의성을 검증하기 위하여 0.05 로 설정하였다.

\section{결 과}

\section{1. 배가로근의 두께 변화}

각 군의 배가로근의 근두께에 대한 반복측정 분산분석 결과 근두께 변화에서 시기별, 시기와 군 간 상호작용은 유의한 차이를 보였고 $(\mathrm{p}<0.05)$, 집단 간 차이는 통계학적으로 유의하지 않았다 $(\mathrm{p}>0.05)$ (Table 2, Figure 1).

\section{2. 뭇갈래근의 두께 변화}

각 군의 뭇갈래근의 근두께에 대한 반복측정 분산분석 결과 근두께 변화에서 시기별, 시기와 군 간 상호작용, 집단 간 차이에서 통계학적 으로 유의한차이를 보였다 $(\mathrm{p}<0.05)$ (Table 2, Figure 2).

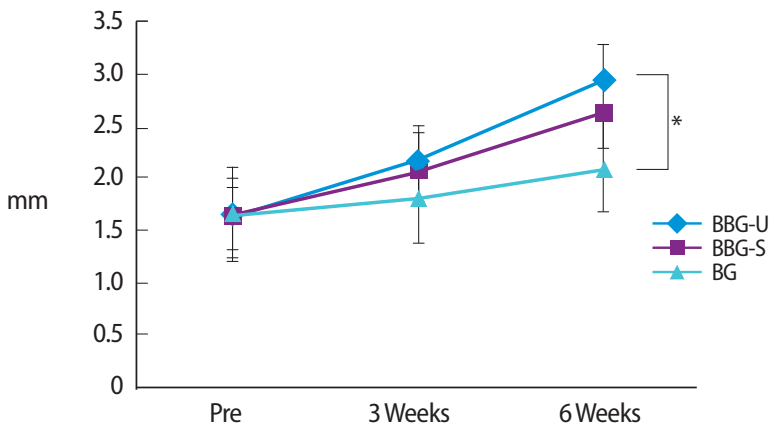

Figure 2. Comparison of multifidus muscle thickness.

고 찰

본 연구는 지지면과 혈류 제한 운동을 이용하여 몸통 I 형 근섬유의 두께 변화를 알아보기 위해 세 그룹으로 나누어 6주간 실험을 실시 하였다.

혈류를 제한 한 상태에서 실시하는 저강도 운동은 단백질 합성 개 시(translation initiation) 향상과, ${ }^{26}$ 혈관신생(angiogenesis) 유도 혈관내 피 성인인자(vascular endothelial growth factor, VEGF)를 유의하게 증 가 시켜 ${ }^{27}$ 근육 비대 및 근력 강화에 매우 효과적이다. ${ }^{18}$

혈관 내피 세포는 일산화질소 $(\mathrm{NO})$ 등의 혈관 작용물질을 생산함 으로써 혈관 활성의 조절에 중요한 역할을 하여 모세혈관을 증가시 킨다. ${ }^{28}$ 이러한 변화는 근세포에 빠른 산소공급과 원활한 순환능력 을 증가시켜 지구력 향상을 발생시키고 ATP 생성에 적합하여 풍부 한 에너지원으로 인해 I 형 근섬유 강화에 이득이 있을 것으로 생각 되어, 혈류 제한과 지면 차이에 변화를 주어 초음파를 이용하여 배가 로근과 뭇갈래근의 근두께 변화를 실험을 시행하였다. 실험에 이용 된 초음파는 심부 근육의 구조적 변화를 측정하는데 꼭 필요한 장비 이며, ${ }^{29}$ 팔 다리 근육이나 골반 바닥 근육, 가로막 근육의 비대를 측정 하는데 신뢰성과 타당도가 입증되었다..$^{30}$

배가로근의 두께 변화에 대한 반복측정 결과 시기별, 시기와 군간 상호작용에서 유의한 차이가 있었고 $(\mathrm{p}<0.05)$, 집단 간 차이는 없었으 
며( $\mathrm{p}>0.05)$, 뭇갈래근은 시기별, 시기와 군 간 상호작용, 집단 간에서 유의한 차이를 보였다 $(\mathrm{p}<0.05)$. 배가로근의 결과를 보면 상호작용에 선 유의하지만 주 효과에서 유의하지 않았다. 이러한 현상은 가면효 과(masking effect)이며 상호작용이 주 효과를 가리는 효과 때문에,31 이러한 결과가 발생한 것으로 생각된다.

혈류 제한 운동 후 근육 두께 증가를 보고한 선행 연구에서 노인을 대상으로 혈류 제한 레그 프레스 운동(leg press exercise) 적용이 넙다 리네갈래근이 $8 \%$ 모음근에서 $6.5 \%$ 큰볼기근에서 $4.4 \%$ 의 증가되었다 고 보고하였고, ${ }^{18} 16$ 명의 성인을 대상으로 다리에 혈류 제한 적용 후 2 주간 걷기 운동만으로 무릎의 굽힘력과 MRI 검사로 넙적다리의 둘 래가 유의하게 증가되었다고 보고하였다. ${ }^{32} \mathbb{I}$ 형 근섬유를 대상으로 한 선행 연구와 I형 섬유를 대상으로 한 본 연구가 비슷한 결과를 보 였다. 혈류 제한 운동은 지근섬유를 포함한 속근섬유의 동원을 증가 시켜 운동단위를 증가 시키며, ${ }^{33}$ 근생검(muscle biopsy) 연구에서 I형 섬유(5.9\%)보다, II 형 섬유(27.6\%) 비대를 확인하였다. ${ }^{34}$ 혈류 제한 연구 의 경우 대부분 I형 섬유보다 II형 섬유에서 효과적이었다. 하지만 본 연구에서의 이러한 결과는 지지면을 이용하여 감각 유입이 보다 감소되어 BBG-S보다 BBG-U에서 시너지 효과가 발생하여 두께 변화 가 발생한 것으로 생각된다.

뭇갈래근의 두께 증가 이유는 교각 운동 방법에서 찾을 수 있다. 몸통을 들어 올릴 때 골반이 뒤쪽 기울임을 하게 되며 이로 인한 불 안정해진 몸통부 안정성을 유지를 위해 뭇갈래근이 많은 수축을 하 여 시기와 군간 상호작용에서 유의한 차이를 보였다. I형 근섬유 두 께 증가와 관련된 연구 중 뭇갈래근의 변화는 아니지만 Park 과 Kim ${ }^{19}$ 는 6주간 혈류 제한 후 짐볼에서 몸통 안정화 운동이 I 형 근섬유인 배가로근의 두께가 시기와 군 간 상호작용에서 유의한 차이가 없었 다고 보고 하여, 본 연구와 차이가 있었다. 선행 연구는 불안정면에서 혈류 차단으로 인한 변화를 확인한 반면, 본 연구는 지지면과 혈류 압력, 혈류 차단 차이에 의한 결과로 생각된다. 측정 시기 변화를 살 펴 보면 BG에 비해 BBG-U와 BBG-S에서 두께 증가가 발견되었고, 3 주 후부터는 BBG-S 보다 BBG-U에서 증가 폭이 커졌다. $150 \mathrm{mmHg}$ 이 상의 압력이 근육 단면적 증가에 이득이 있다고 한 메타분석 결과처 럼, ${ }^{35}$ 본 연구는 3 주 후부터 $150 \mathrm{mmHg}$ 이상의 압력을 이용하였고, 선 행연구는 $150 \mathrm{mmHg}$ 이하의 압력으로 인해 발생한 차이로 생각된다. 또한, $1 \mathrm{RM} 20 \%$ 의 운동 강도보다 $1 \mathrm{RM} 30 \%$ 의 운동 강도에서 근력에 이득이 있다고 하였는데, ${ }^{35}$ 불안정면에서 교각운동이 다른 군들에 비 해 감각 유입이 적어 균형을 유지하기 위해 지속적인 수축을 하여 이 러한 결과를 보인 것으로 생각된다.

지구력과 I형 근섬유는 밀접한 관련이 있다. 이러한 지구력 관련 연구를 살펴보면 $\mathrm{Kim}^{36}$ 은 혈류 차단 군과 차단하지 않은 군으로 1 분 간 발목 운동을 실시 한 후 Hoffimann 반사를 이용하여 지근 $\alpha$-운동
신경원의 변화 연구에서 두 군간 차이가 없다고 보고 하여, 지근의 a운동신경원과 혈류제한 운동은 관련성이 없는 것으로 나타났다. 하지 만 또 다른 연구에서는 혈류 제한 운동은 지구력 개선에 이득이 있다 고 보고하였다. ${ }^{37,38}$ 이러한 지구력 개선은 I형 근섬유와 관련된 모세 혈관 증식으로 인한 결과로 해석된다. 지구력 운동은 모세혈관의 발 달과 마이오글로빈, 글리코겐의 변화가 발생된다. 혈류 제한 운동 역 시 I형 근섬유 주위의 모세혈관 밀도를 증가 시켜 에너지 대사와 생 화학적 변화로 인해 지속적인 근수축이 가능하여 배가로근과 뭇갈래 근의 근두께 증가가 발생된 것으로 생각된다. 혈관 반응을 통한 근두 께 증가에 대한 기전 이해는 부족하지만 지지면차이와혈류제한차이 로 인한 I형 섬유의 변화는 임상적 의미가 있으며 혈류 제한으로 인 한 지구력 증가에 관련된 기전 연구가 필요한 것으로 생각된다.

본 연구는 특정 연령층과 적은 대상자로 한정하여 일반화하여 해 석하기엔 무리가 있고 지구력 개선 기전적 이해를 해석하지 못하는 점이 제한점으로 남는다. 차후에 기전 관련 연구가 필요할 것으로 생 각되며, I형 근섬유 강화를 위한 기초자료와 임상에서 혈류 제한을 이용한 몸통 안정화 중재 방법으로 유용할 것으로 보인다.

\section{참고문헌}

1. Muscolino JE, Cipriani S. Pilates and the "powerhouse"-I. J Bodyw Mov Ther. 2004;8(1):15-24.

2. Hodges P, Gurfinkel V, Brumagne $S$ et al. Coexistence of stability and mobility in postural control: evidence from postural compensation for respiration. Exp Brain Res. 2002;144(3):293-302.

3. Stevens VK, Bouche KG, Mahieu NN et al. Trunk muscle activity in healthy subjects during bridging stabilization exercises. BMC Musculoskelet Disord. 2006;20(7):75.

4. Stuge B, Laerum E, Kirkesolag G et al. The efficacy of a treatment program focusing on specific stabilizing exercises for pelvic girdle pain after pregnancy: a randomized controlled trial. Spine. 2004;29(4):351-9.

5. Stevens VK, Coorevits PL, Bouche KG et al. The influence of specific training on trunk muscle recruitment patterns in healthy subjects during stabilization exercises. Man Ther. 2007;12(3):271-9.

6. Lee WJ, Park S, Park JW. Influence of trunk stabilization exercise upon the lumbar stabilization and foot pressure in patients with back pain. J Kor Phys Ther. 2014;26(1):21-6.

7. Shim HB, Cho HY, Choi WH. Effects of the trunk stabilization exercise on muscle activity in lumber region and balance in the patients with hemiplegia. J Kor Phys Ther. 2014;26(1):33-40.

8. Yeom JN, Lim CG. Change of static and dynamic foot pressure after trunk stabilization exercises in children with spastic diplegic cerebral palsy. J Kor Phys Ther. 2014;26(4):274-9.

9. Yu JY, Park JC, Jeong JG. Influence of multi-directional dynamic stabilization exercise on thickness of abdominal muscle. J Kor Phys Ther. 2016;28(4):249-53.

10. Park JC, Yu JY, Hwang TY et al. Effects of stabilzation exercise on the structural characteristics of trunk muscles between stable and unstable 
surfaces. J Kor Phys Ther. 2016;28(5):297-302.

11. Escamilla RF, Lewis C, Bell D et al. Core muscle activation during swiss ball and traditional abdominal exercises. J Orthop Sports Phys Ther. 2010;40(5):265-76.

12. Lehman GJ, Hoda W, Oliver S. Trunk muscle activity during bridging exercises on and off a swissball. Chiropr Osteopat. 2005;13(1):14.

13. Choi BC, Kim H. Effect of lumbar stabilization exercise on balance ability. Korea Journal of Sports Science. 2009;18(2):1147-56.

14. American College of Sports Medicine. American college of sports medicine position stand. Progression models in resistance training for healthy adults. Med Sci Sports Exerc. 2009;41(3):687-708.

15. Werndom M, Augustsson J, Raastad T. Ischemic strength training: a lowload alternative to heavy resistance exercise? Scand J Med Sci Sports. 2008;18(4):401-16.

16. Karabulut M, Abe T, Sato Y et al. The effects of low-intensity resistance training with vascular restriction on leg muscle strength in older man. Eur J Appl Physiol. 2010;108(1):147-55.

17. Loenneke JP, Welson JM, Marin PJ et al. Low intensity blood flow restriction training: a meta-analysis. Eur J Appl Physiol. 2012;112(5):184959.

18. Yasuda T, Fukumura K, Fukuda T et al. Muscle size and arterial stiffness after blood flow-restricted low-intensity resistance training in older adults. Scand J Med Sci Sports. 2014;24(5):799-806.

19. Prak JC, Kim YN. Impact of waist stabilization exercise with blood flow pestriction on white area index of trunk muscle thickness density. J Kor Phys Ther. 2016;28(2):136-41.

20. Patterson SD, Ferguson RA. Enhancing strength and postocclusive calf blood flow older people with training with blood-flow restriction. J Aging Phys Act. 2011;19(3):201-13.

21. Jun JY, Park MC. The effect of stair exercise with restriction blood flow on knee extensor muscle. J Korean Soc Phys Med. 2015;10(4):9-14.

22. Sumide T, Sakuraba K, Sawaki K et al. Effect of resistance exercise training combined with relatively low vascular occlusion. J Sci Med Sport. 2009;12(1):107-12.

23. Takarada Y, Tsuruta T, Ishii N. Cooperative effects of exercise and occlusive stimuli on muscular function in low-intensity resistance exercise with moderate vascular occlusion. Jpn J Physiol. 2004;54(6):585-92.

24. Sakuraba K, Ishikawa T. Effect of isokinetic resistance training under a condition of restricted blood flow with pressure. J Orthop Sci. 2009; 14(5):631-9.

25. Hodges PW, Gandevia SC. Changes in intra-abdominal pressure during postural and respiratory activation of the human diaphragm. J Appl Physiol. 2000;89(3):967-76.

26. Abe T, Loenneke JP, Fahs CA et al. Exercise intensity and muscle hypertrophy in blood flow-restricted limbs and non-restricted muscle: a brief review. Clin Physiol Funct Imaging. 2012;32(4):247-52.

27. Takano H, Morita T, Iida H et al. Hemodynamic and hormonal responses to a short-term low-intensity resistance exercise with the reduction of muscle blood flow. Eur J Appl Physiol. 2005;95(1):67-73.

28. Okamoto T, Masuhara M, Ikuta K. Effects of muscle contraction timing during resistance training on vascular function. J Hum Hypertens. 2009; 23(7):470-8.

29. Rankin G, Stokes M, Newham DJ. Size and shape of the posterior neck muscles measured by ultrasound imaging: normal values in males and females of different ages. Man Ther. 2005;10(2):108-15.

30. Braekken IH, Majida M. Engh ME et al. Morphological changes after pelvic floor muscle training measured by 3 -dimensional ultrasonography: a randomized controlled trial. Obstet Gynecol. 2010;115(2pt1): $317-24$.

31. Sung NK. Analysis and experiment of repetitive measurement. Paju, Free Academy, 1997:113.

32. Chun JM. The effects of pressurization training with short-term walk on cardiorespiratory responses and skeletal muscle function. Kyung Hee University. Dissertation of Doctorate Degree. 2008.

33. Nielsen JL, Aagaard P, Bech RD et al. Proliferation of myogenic stem cells in human skeletal muscle in response to low-load resistance training with blood-flow restriction. J Physiol. 2012;1(590):4351-61.

34. Yasuda T, Abe T, Soto Y et al. Muscle fiber cross-sectional area is increased after two weeks of twice daily KAATSU-resistance training. Int J KAATSU Training Res. 2005;1(2):65-70.

35. Slysz J, Stultz J, Burr JF. The efficacy of blood flow restricted exercise: a ststematic review \& meta-analysis. J Sci Med Sport. 2016;19(8):669-75.

36. Kim JS. Changes of $\alpha$-motor neuron excitability after low-intensity exercise with transient restriction of blood flow. J Korean Soc Phys Med. 2015;10:63-69.

37. Evans C, Vance S, Brown M. Short-term resistance training with blood flow restriction enhances microvascular filtration capacity of human calf muscles. J Sports Sci. 2010;28(9):999-1007.

38. Hunt JE, Galea D, Tufft G et al. Time course of regional vascular adaptations to low load resistance training with blood flow restriction. J Appl Physiol. 2013;115(3):403-11. 